\title{
Development of a Manufacturing Web-Based Learning System for Promoting Practice Ability
}

\author{
Min Jou \\ Associate Professor, Department of Industrial Education, National Taiwan Normal University
}

\section{Introduction}

Since the early 1980s, computers have entered the manufacturing educational arena. Increasingly, general purpose tools, such as computer-aided drawing and design packages, computer-aided manufacturing and simulation packages, and computer-aided analysis packages, were developed as valuable computer environments for improving manufacturing productivity ${ }^{1,2}$. The emerging technologies require new knowledge and skills. This places a serious responsibility on engineering educators to provide students with the scientific principles of new technologies, and familiarize them with their impact on the modern manufacturing processes. Manufacturing science includes these technical areas: manufacturing technique, manufacturing systems, design and analysis of manufacturing process planning, material handling, monitoring and control, automated inspection, sensors and interfaces, and management. The manufacturing technique covers: turning, milling, drilling, holing ...etc. Much time and cost are used to teach these techniques. Particularly, computerized machines are continuously increasing in use. The development of educating engineers on computerized machines becomes much more difficult than with traditional machines. This is because of the limitation of the extremely expensive cost of teaching. The quality and quantity of teaching cannot always be promoted in this respect. The traditional teaching methods cannot respond well to the needs of the future.

The evolution of computer and Internet technologies has made it easy to access learning contents from almost anywhere, anytime, and at user pace ${ }^{3,4}$. In 1994, Bengu ${ }^{5,6}$ developed a suite to provide comprehensive engineering education for freshmen in manufacturing processes and systems, and in concurrent engineering. The focus was to develop a support mechanism to deliver the courseware of manufacturing through the www. Since manufacturing education is so vital to the creation of the engineer, Bengu \& Swart $^{7}$ created a learning $^{-}$ process based on total quality management (TQM) and critical thinking (CT) concepts (Figure 1). Their study takes advantage of computer and information technology to enhance the delivery of education through computer-aided teaching and learning tools. A basic proposed framework for the course brings together assembled subject material using various media. In order to achieve the effective use of this new teaching and learning methods, the course proposed includes: on-line lectures, audio-video education tools, interactive computer software, on-line assignments and exams, information about faculty, on-line evaluation tools to obtain student feedback, and to improve teaching quality.

The advance in the optical-fiber network makes real-time transmission of a large amount of data, such as three-dimensional models or video images, possible between remote places. In particular, by connecting virtual environments through the broadband network ${ }^{8}$, a three-dimensional virtual world can be shared between remote places.

\section{System Architecture}

In order to provide students an e-learning system as realistic as possible and expandable to the entire system, the developed system is based on N-tier architecture, as shown in Figure 2. The application tier side consists of a web server and a Java application server. A presentation tier is a client-side that comprises the HTML, XML, and 3D Web player plug-in. The client, which runs in a Web browser, provides a student interface that handles input (allowing students to enter data, access to course materials, make decisions, and interact with 3D virtual laboratory), and output (displaying results, simulation). The web server performs actions and computations based on student input by using XML and JSP language. The application server reads and writes to the databases by JavaBean, and interfaces with external software packages (CAD/CAM and CAE). 


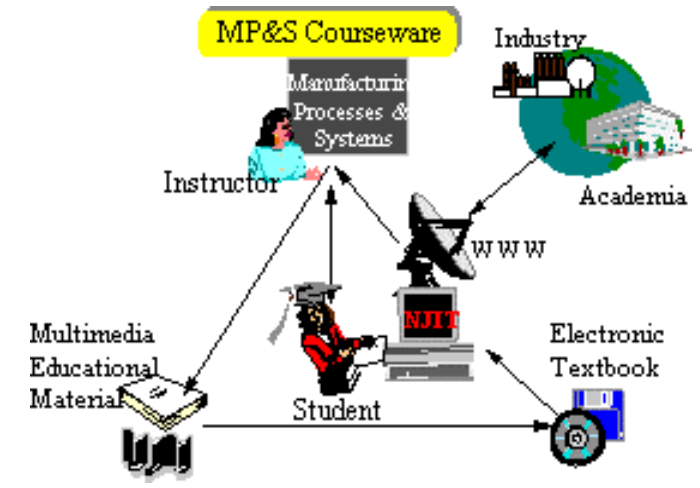

Figure 1 Computer Aided Learning \& Teaching Tools ${ }^{7}$

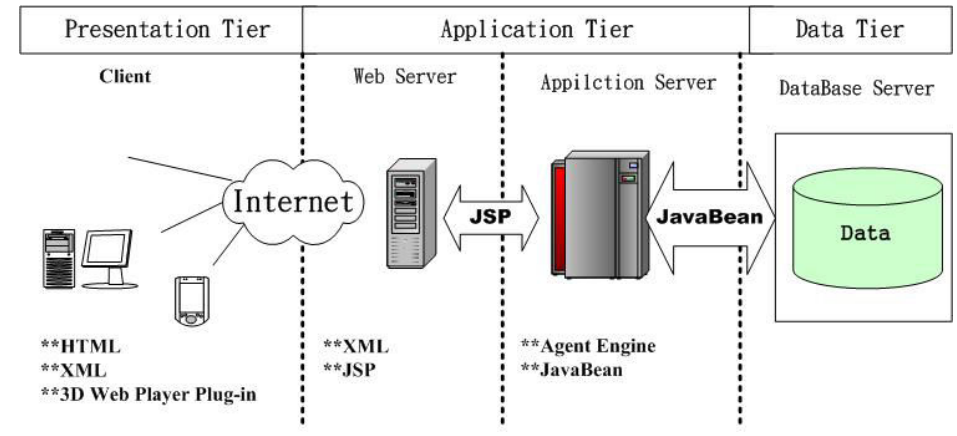

Figure 2 Architecture of Manufacturing E-Learning System (eCAM)

The content of the course is primarily presented with Web pages which are written by HTML. In order to move courses from one system to another, and extract and/or perform automated processing on the documents, standardized definitions for course structures are necessary. To meet requirements, Extensible Markup Language (XML) is used to develop course structures. In order to get cross-platform application, JAVA language is used in programming to develop an interactive Web page.

Students access eCAM system via the interactive Web page as shown in Figure 3. The four modules in this system are Management, Evaluation, Basic Machining Skill, and Product-Oriented Manufacturing. An instructor can create course materials in the management module. A student can learn the basic technologies, such as turning, milling, and drilling, from the basic machining skill module. In addition, a student can learn machining method for a specific product through the product-oriented manufacturing module. Finally, a teaching evaluation module is created to evaluate student practice ability.

One of the challenges for learning machining techniques through Internet, is how to present spatial information to students to promote student practice ability? In this research, virtual reality (VR) techniques are adopted to describe various activities of machining in terms of translation, rotation, combination, and decomposition of geometric objects.

The purpose of the learning agent developed in this system is to monitor student actions, and give the correct information when incorrect actions or answers are input. In order to provide media contents for multi-users, eliminate the delay of casting processes, and increase cast quality, the SureStream is employed to manipulate stream files for casting. The stream media contents are controlled and cast by the Pear-to-Pear casting method to meet the multi-cast purpose.

The evaluation of learning is an important part of developing course content and teaching method. Student feedback is the key to understanding the progress, quantity, and quality of their learning. In this system, a pre-test is created to measure the student's capability. Appropriate course content and processes will be assigned 
to the student based on the measures of the pre-test. A post-test mechanism is also designed to evaluate student ability on machining techniques, and to collect useful information to study learning attitude using Web pages.

The database created in this system includes management, evaluation, and manufacturing. The manufacturing database contains information such as material, cutting tool, part feature, and machining feature.

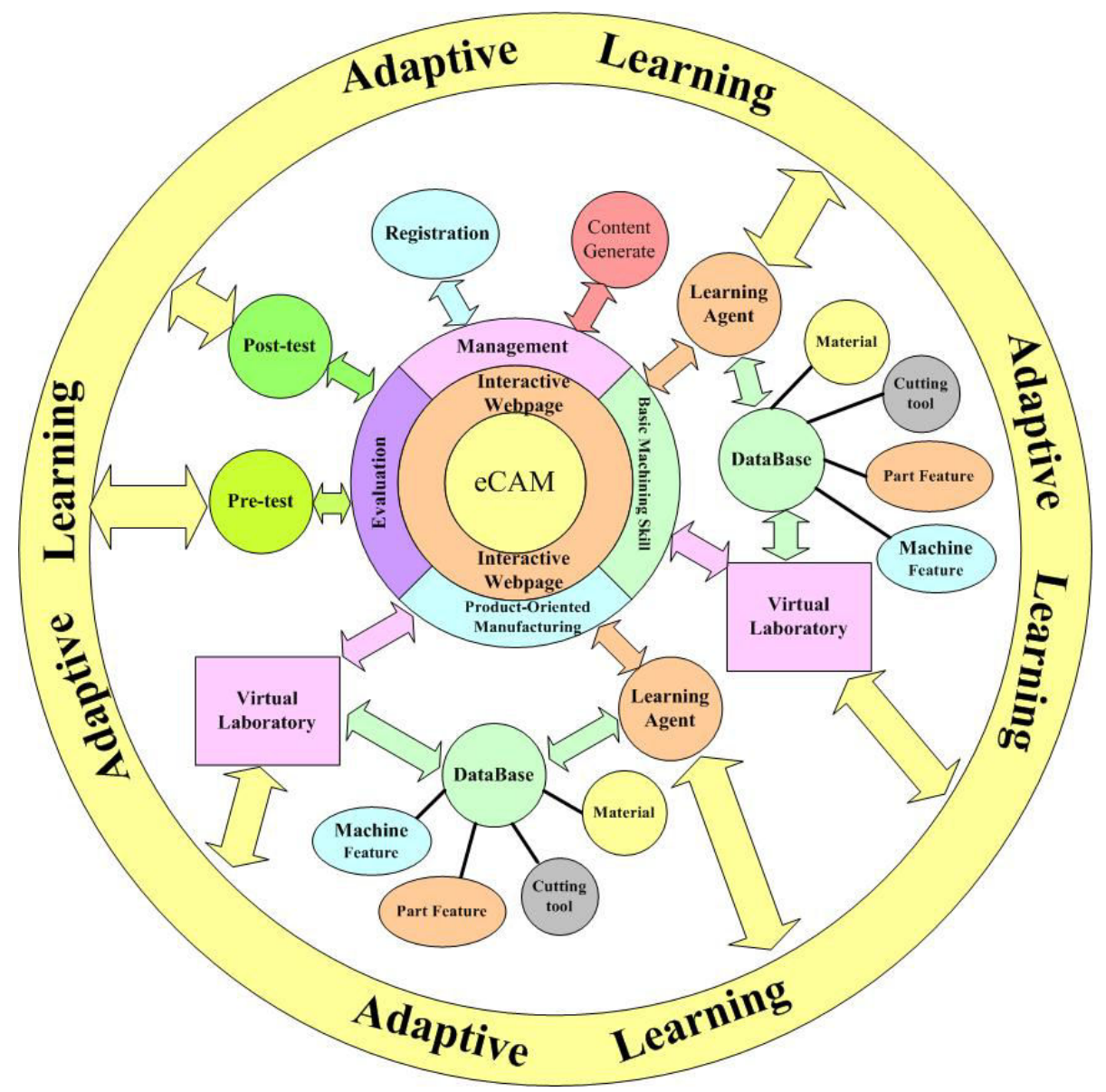

Figure 3 Framework of Manufacturing E-Learning System (eCAM)

\section{Course Model: GT code}

The course model developed in this research is based on two methodologies: manufacturing feature and group technology. Manufacturing features are those which are meaningful to the manufacturing. Some manufacturing features are hole, groove, countersink, counter bore, pocket, chamfer, fillet, etc. Figure 4 shows the manufacturing features of a turning process. The desired part is subtracted from the stock to obtain the finished part by removing volumes "a", "b", "c", "d", and "e". The same method is applied to the milling process where the finished part is obtained by machining manufacturing features "a", "b", "c", and "d", as shown in Figure 5. In order to let students learn and practice the machining methods for basic manufacturing features, a module called $\ulcorner$ Basic Machining Skill $\lrcorner$ was developed, as shown in Figure 3 . This module provides course material that allows students to study the basic skills (Turning, Milling, and Drilling) of machining basic manufacturing features.

Usually, the geometry of desired parts is not as simple as depicted in Figure $4 \& 5$, which can be machined by turning or milling process only. Complex parts contain various manufacturing features. Therefore, a systematic way to identify manufacturing features from mechanical graphics is needed. In this system, group technology is used to develop a coding method for mechanical parts. The geometry of mechanical parts is represented by ten digit codes, as shown in Figure 6 . The detail coding method for rotational parts is shown in Figure 7. Figure 8 gives an example of the coding process from a designed graphic. The machining method and 
manufacturing process can be generated according to the GT code. Figure 9 shows a turning procedure for machining feature-by-feature to manufacture a desired part. The approach of coding method employed in this research not only enables the learning contents of manufacturing to be standardized, but also lets students learn the machining method of manufacturing features and processes.

\section{Implementation and Results}

This system, called eCAM, provides students a systemic way to learn manufacturing technology, via the client-side graphical user interface, as shown in Figure 10. Students study the overall shape of the part, and specify geometric information of the desired parts, designed as 2D or 3D graphics. The system will automatically analyze the manufacturing features, and generate its GT code, according to the geometric information specified by students. The learning content of the manufacturing processes will be extracted from the database based on the generated GT code. Figure 11 depicts the sequence of the whole procedure.

\subsection{Scenario 1: Basic Manufacturing Features}

Students can learn the machining method for basic manufacturing features from this system. A student can select features of turning process in dialogue, as shown in Figure 12. For example: thread feature is chouse. The learning content of turning thread, including graphics and text, is displayed for the student to learn, as shown in Figure 13. A video is cast to illustrate the real turning process for a thread feature. The purpose of this phase is to let students learn the basic concept of manufacturing features, and improve machining skill.

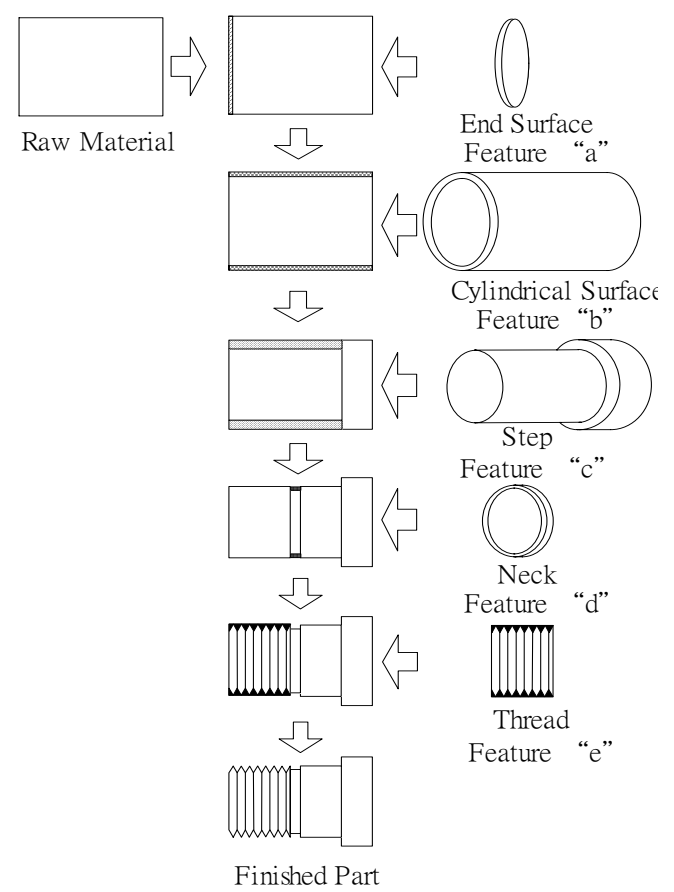

Figure 4 Manufacturing Features of Turning Process 


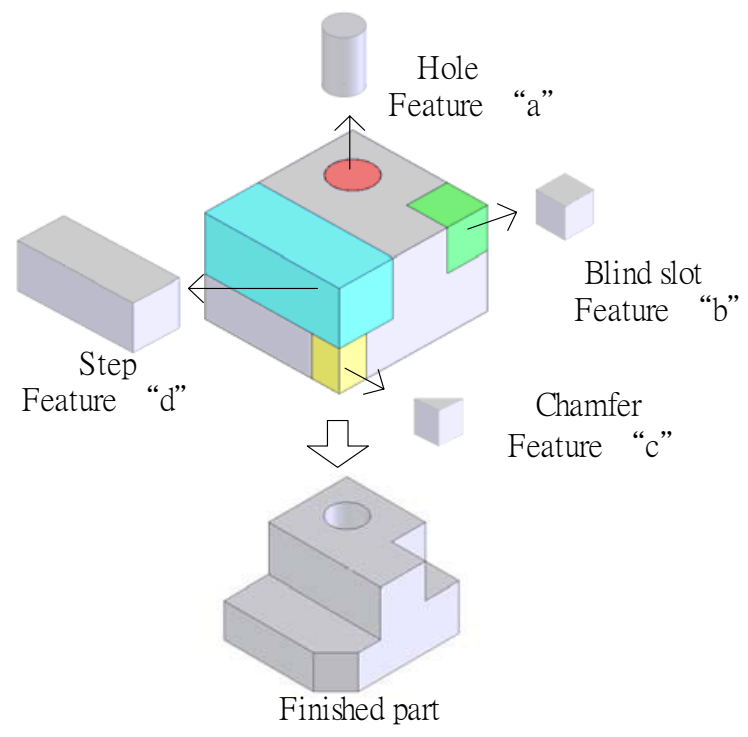

Figure 5 Manufacturing Features of Milling Process

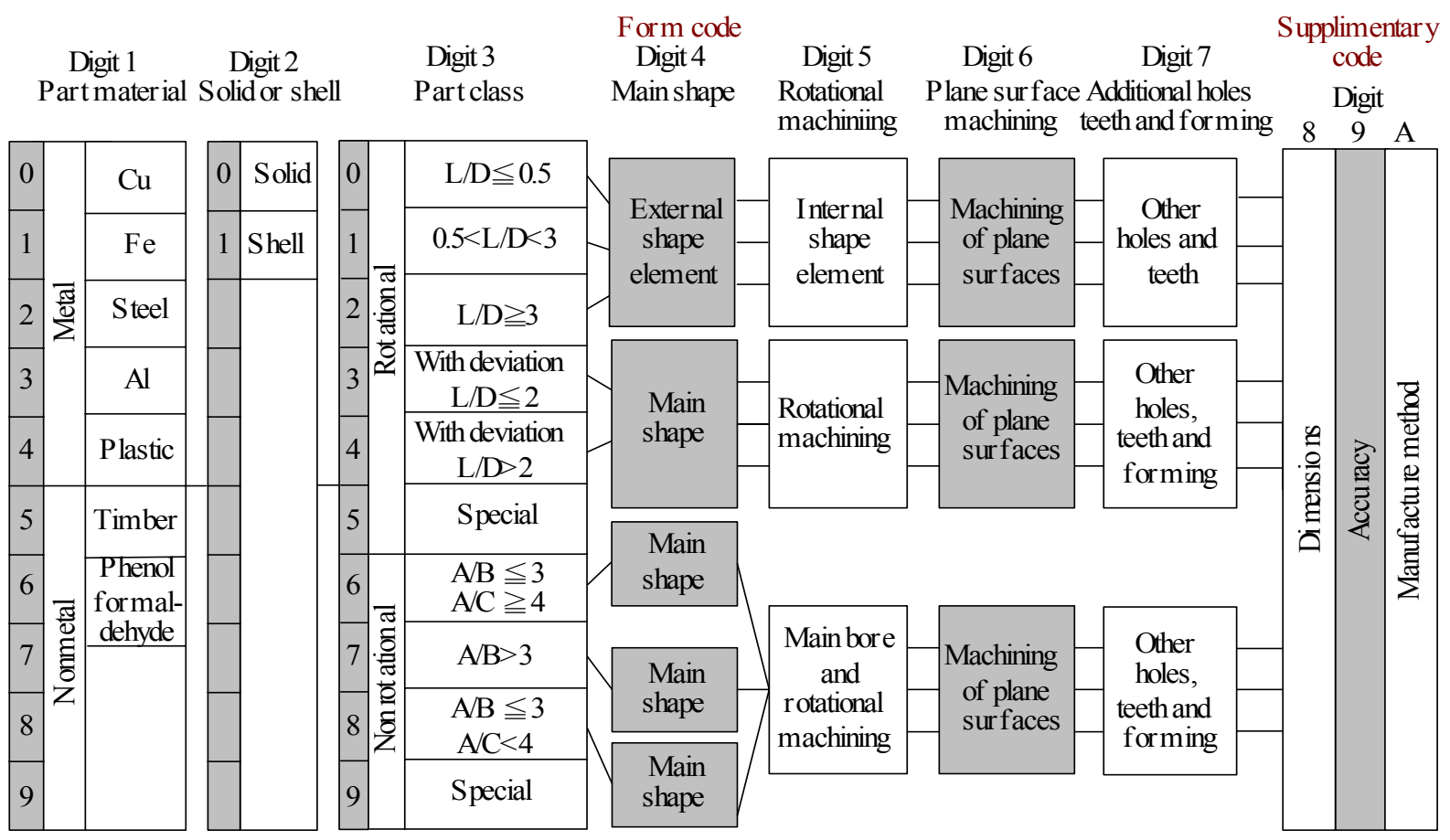

Figure 6 Coding Method for Mechanical Parts ${ }^{9}$ 
Digit 1

\begin{tabular}{|c|c|}
\hline \multicolumn{2}{|c|}{ Material } \\
\hline 0 & $\mathrm{Cu}$ \\
\hline 1 & $\mathrm{Fe}$ \\
\hline 2 & Steel \\
\hline 3 & $\mathrm{Al}$ \\
\hline 4 & Plastic \\
\hline 5 & Timber \\
\hline 6 & $\begin{array}{l}\text { Phen ol } 1 \\
\text { formald - } \\
\text { chy yde }\end{array}$ \\
\hline 7 & \\
\hline 8 & \\
\hline 9 & \\
\hline
\end{tabular}

Digit 3

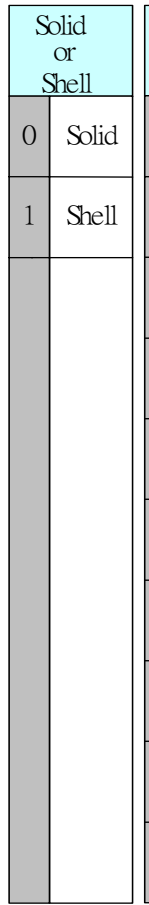

Digit 4

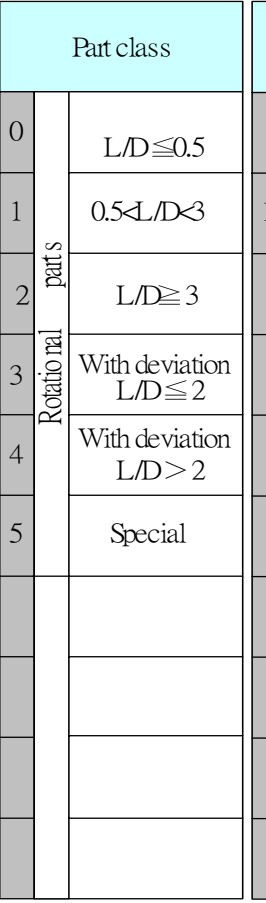

Extemal shape extemal shape $\quad$ intemal shape

Smooth no

shape elements

No shape

1 离 $\begin{aligned} & \text { No shape } \\ & \text { elements } \\ & 0\end{aligned}$

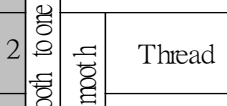

Eunctional

groove

\begin{tabular}{|c|c|c|c|c|}
\hline$\frac{2}{2}$ & Breakthrough & 4 & : & Breakthrough \\
\hline $\begin{array}{l}8 \\
\frac{8}{8} \\
\end{array}$ & Thread & 5 & $\begin{array}{l}10 \\
0 \\
0 \\
0 \\
0\end{array}$ & Thread \\
\hline$\frac{2}{3}$ & $\begin{array}{l}\text { Functional } \\
\text { groove }\end{array}$ & 6 & $\frac{\text { 总 }}{\frac{2}{2}}$ & $\begin{array}{l}\text { Functional } \\
\text { groove }\end{array}$ \\
\hline & $\begin{array}{l}\text { Functional } \\
\text { cone }\end{array}$ & 7 & & $\begin{array}{l}\text { Functional } \\
\text { cone }\end{array}$ \\
\hline & $\begin{array}{c}\text { Operating } \\
\text { thread }\end{array}$ & 8 & & $\begin{array}{c}\text { Operating } \\
\text { thread }\end{array}$ \\
\hline & All others & 9 & & All others \\
\hline
\end{tabular}

Digit 6

\begin{tabular}{|c|c|}
\hline \multicolumn{2}{|c|}{$\begin{array}{c}\text { Plane surface } \\
\text { machining }\end{array}$} \\
\hline 0 & $\begin{array}{l}\text { No surface } \\
\text { machining }\end{array}$ \\
\hline 1 & $\begin{array}{l}\text { Surface plane and } / / 0 r \\
\text { curved in oned ireation } \\
\text { ex ternal }\end{array}$ \\
\hline 2 & $\begin{array}{l}\text { Ex tern al plane surfarae } \\
\text { related by g gradu uation } \\
\text { aro und the irrcle }\end{array}$ \\
\hline 3 & $\begin{array}{c}\text { Extemal groove } \\
\text { and/or slot }\end{array}$ \\
\hline 4 & $\begin{array}{l}\text { Extemal spline } \\
\text { (polygon) }\end{array}$ \\
\hline 5 & $\begin{array}{l}\text { Exterm al plane } \\
\text { surface and dor } \\
\text { slot,ex term al sp line }\end{array}$ \\
\hline 6 & $\begin{array}{l}\text { Intemal plane } \\
\text { surface and/or } \\
\text { slot }\end{array}$ \\
\hline 7 & $\begin{array}{l}\text { Intemal spline } \\
\text { (polygon) }\end{array}$ \\
\hline 8 & $\begin{array}{l}\text { In ternal and ex ternal } \\
\text { poly gon, groove } \\
\text { and/or slot }\end{array}$ \\
\hline & All others \\
\hline
\end{tabular}

Digit 7

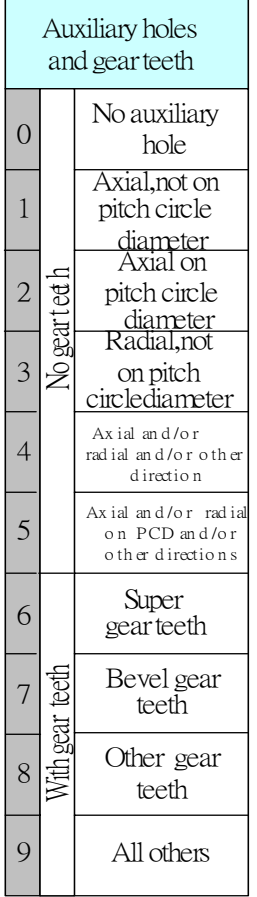

Figure 7 Coding for Rotational Parts ${ }^{9}$

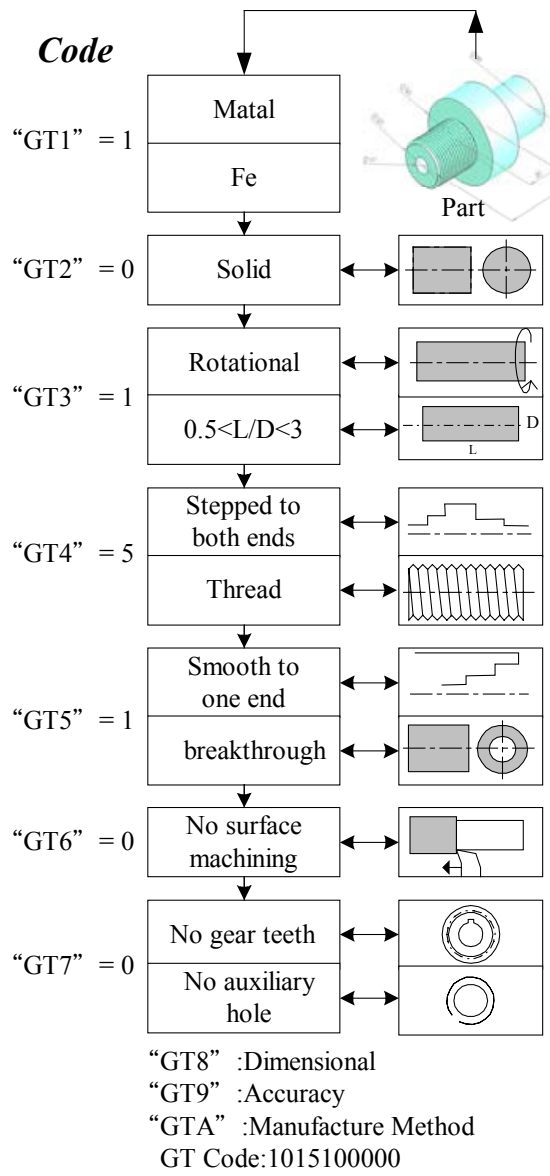

Figure 8 Coding Process for a Rotational Part 


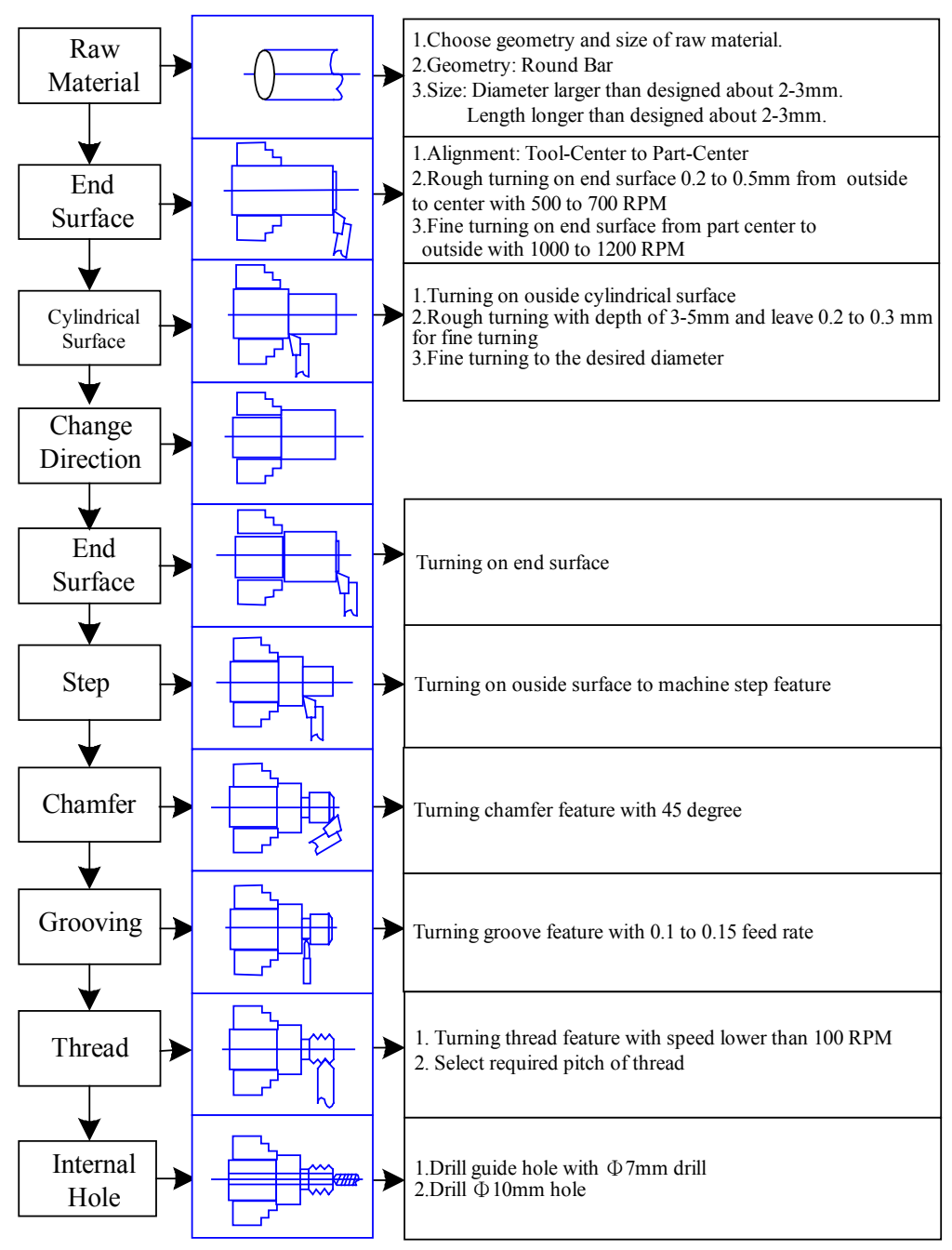

Figure 9 Turning Process for a Rotational Part

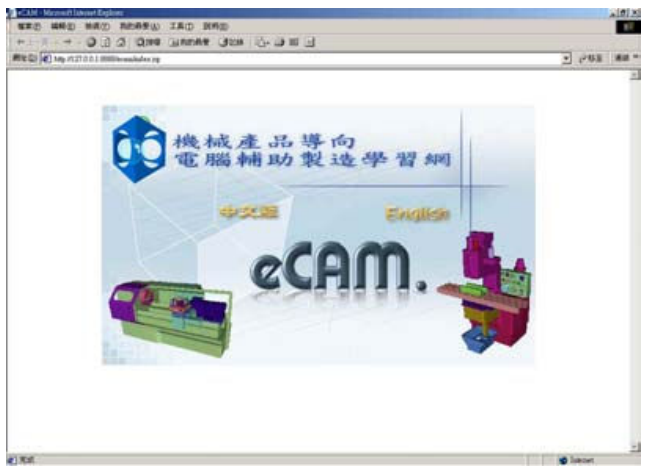

Figure 10 Web Page of eCAM system

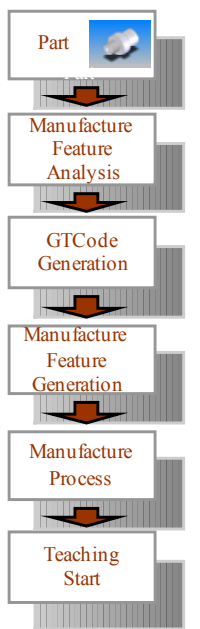

Figure 11 Learning Content Generation Procedures 


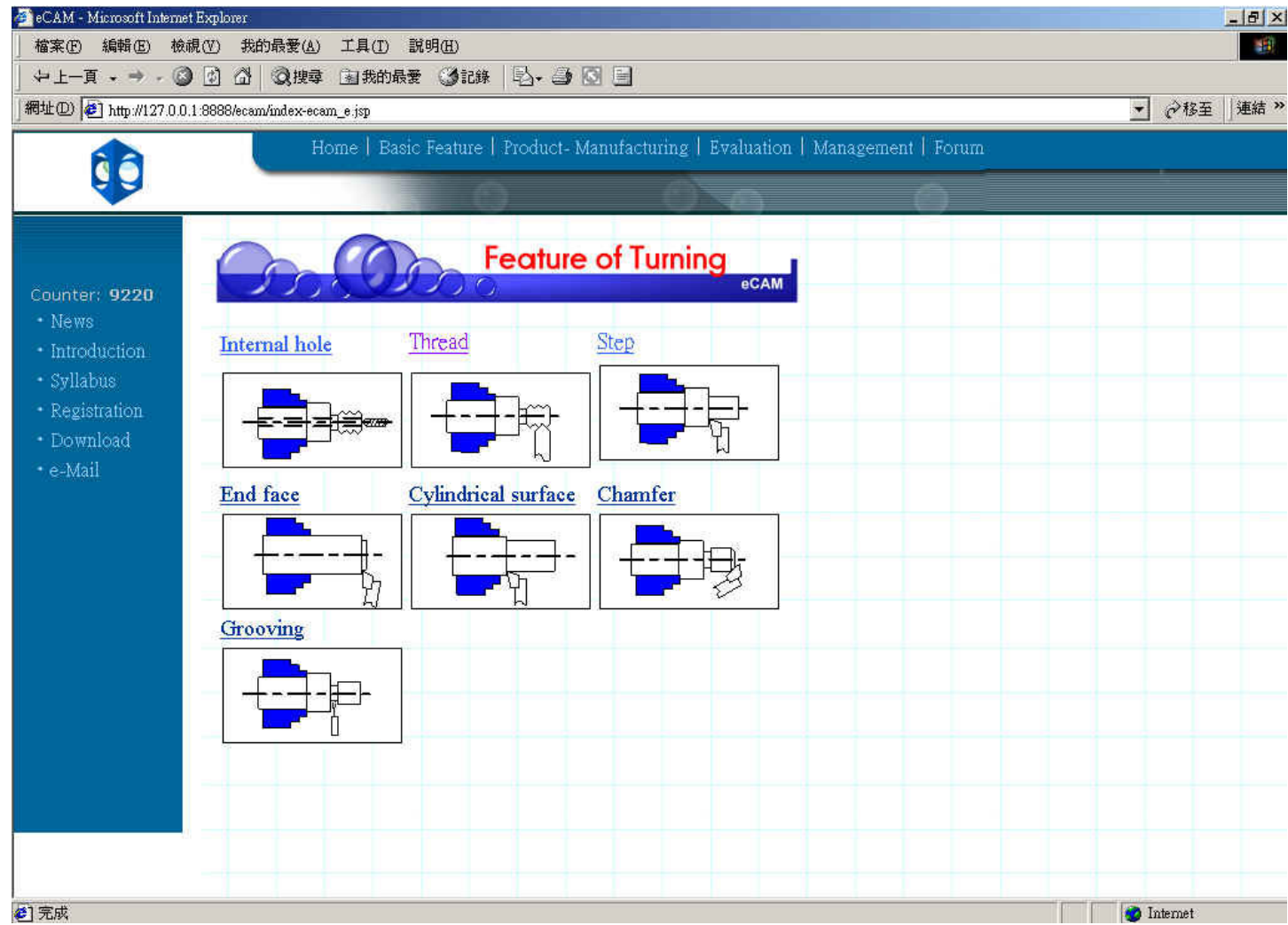

Figure 12 Machining Basic Manufacturing Features

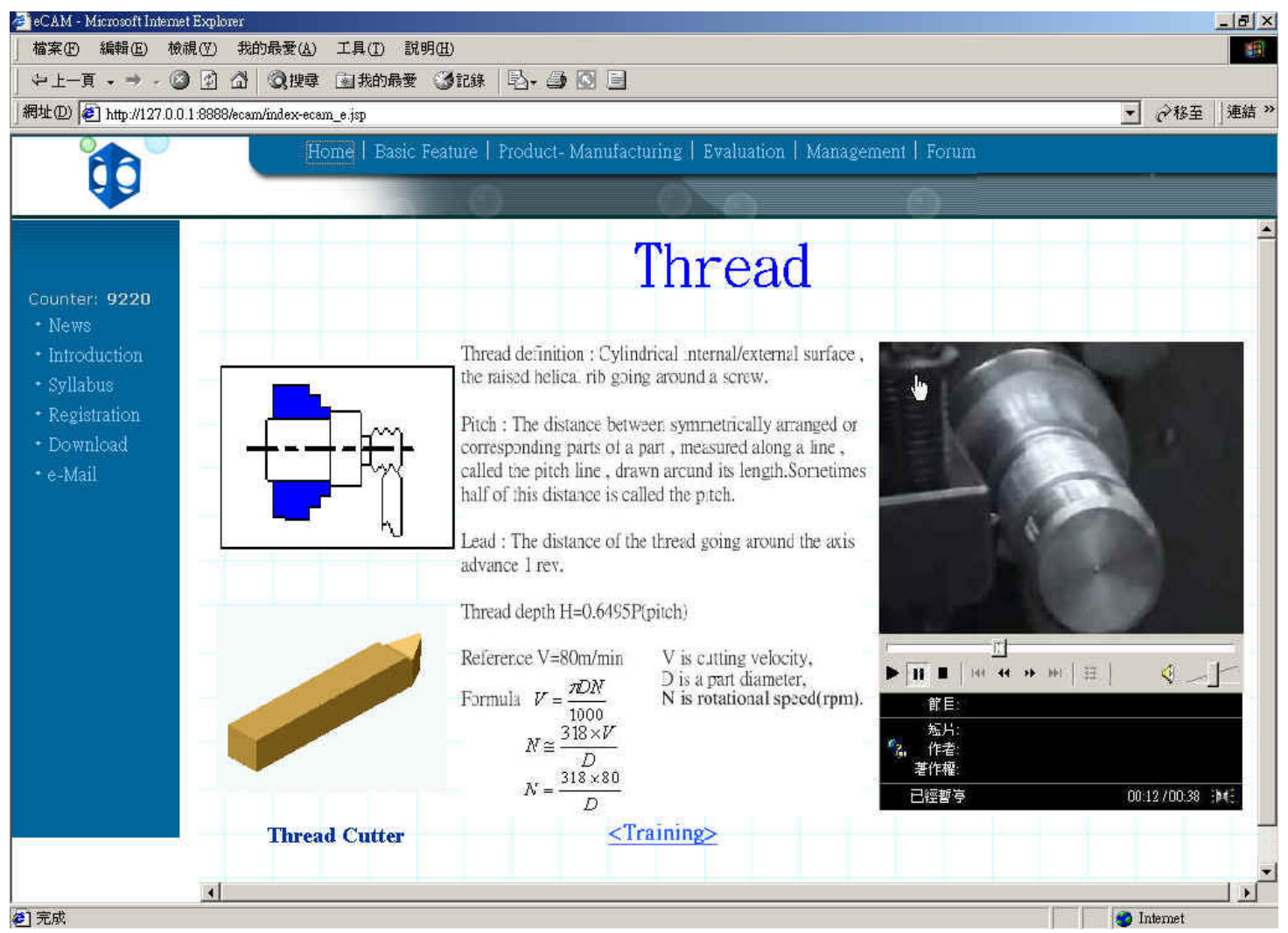

Figure 13 Learning Content of Thread Turning 


\subsection{Scenario 2: Product-Oriented Learning (Phase I)}

Students can go further to learn manufacturing methods for a complex part (Figure 14), once they have the capability of machining basic manufacturing features. In this step, the geometric information has to be read and specified, as described in dialogue in Figure 15.

\subsection{Scenario 3: Product-Oriented Learning (Phase II)}

This system will create a GT code based on the geometric information specified, and generate the manufacturing features required to fabricate the desired part, as shown in Figure 16. The possible machining procedures are displayed to students in Figure 17. The system will indicate the appropriate procedure and give the reasons for decision making. In this phase, one objective is to give the student the ability to extract the manufacturing features for a complex part, from a mechanical drawing in either 2D or 3D. The concept of manufacturing process planning can also be brought to students.

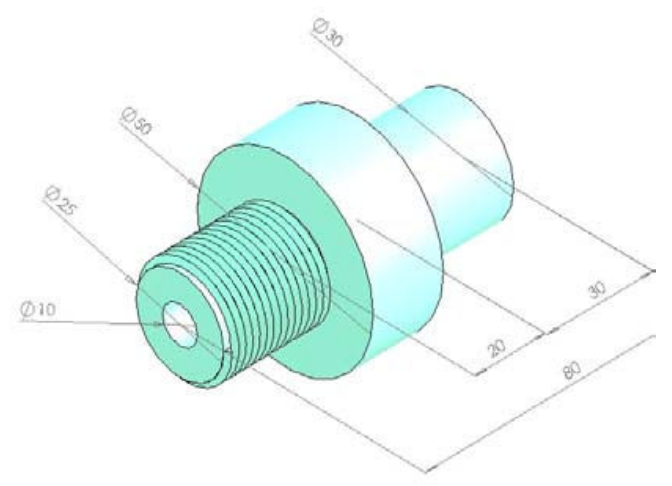

Figure 14 A Complex Part with Turning Features

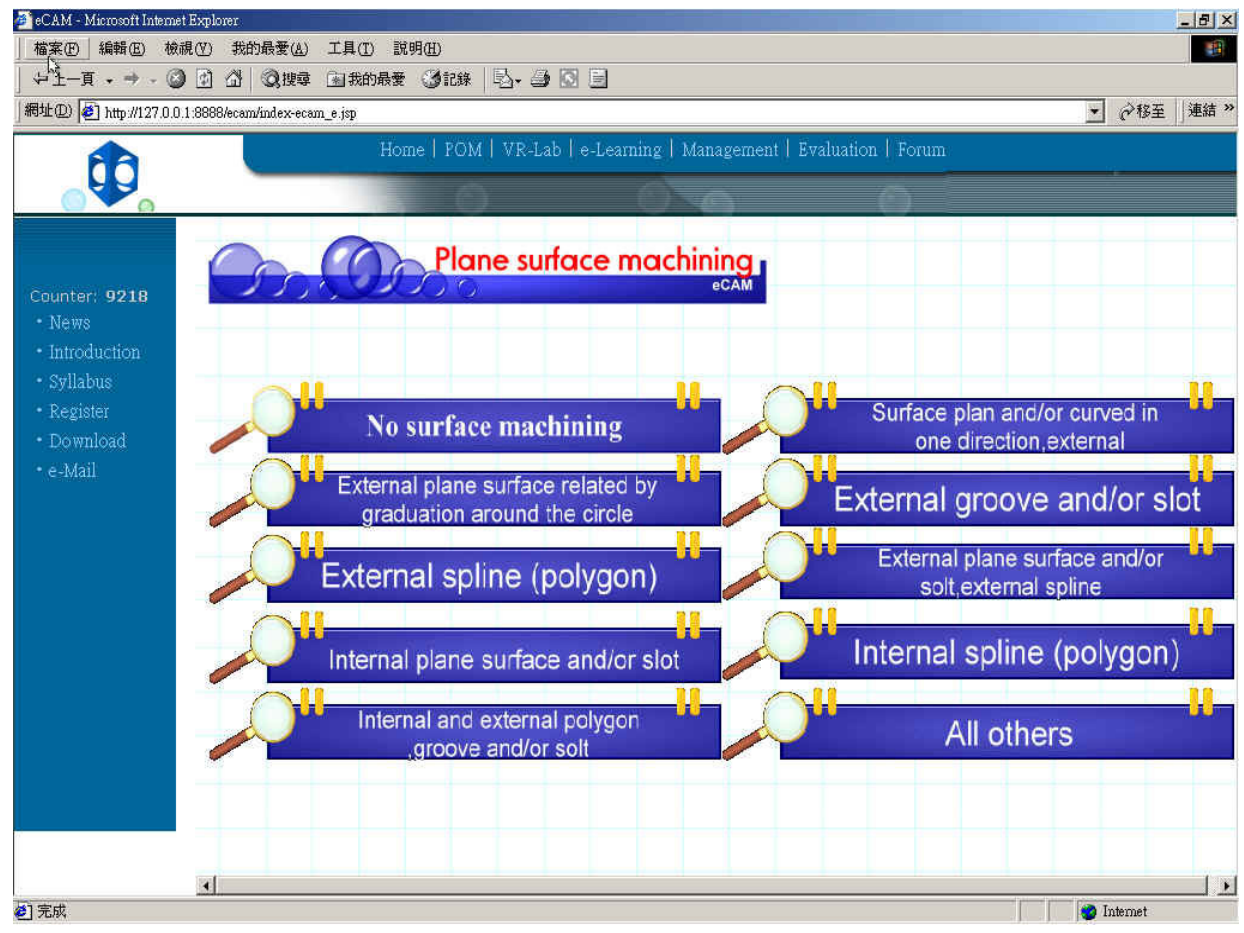

Figure 15 Specification of Part Geometry 


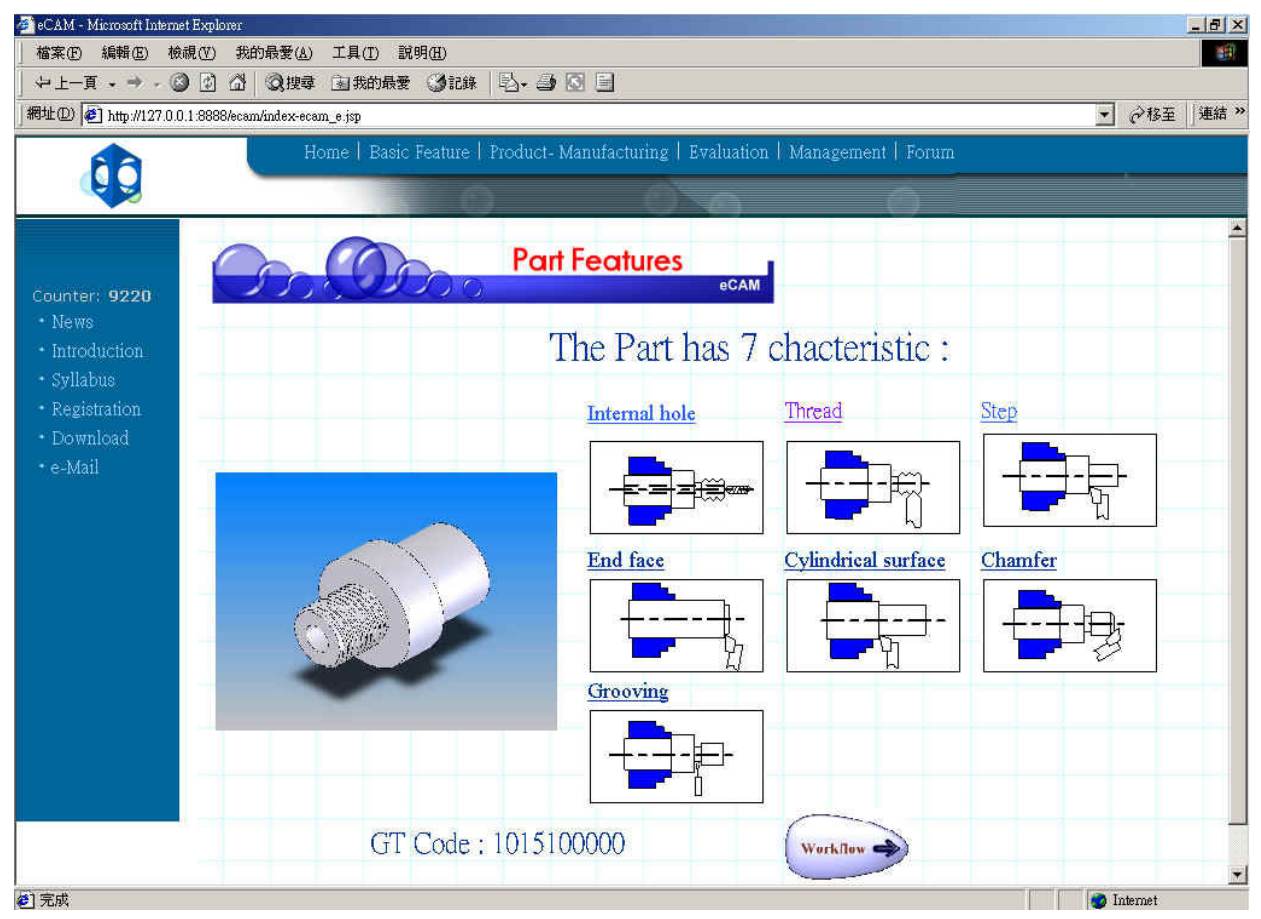

Figure 16 Manufacturing Features for a Complex Part

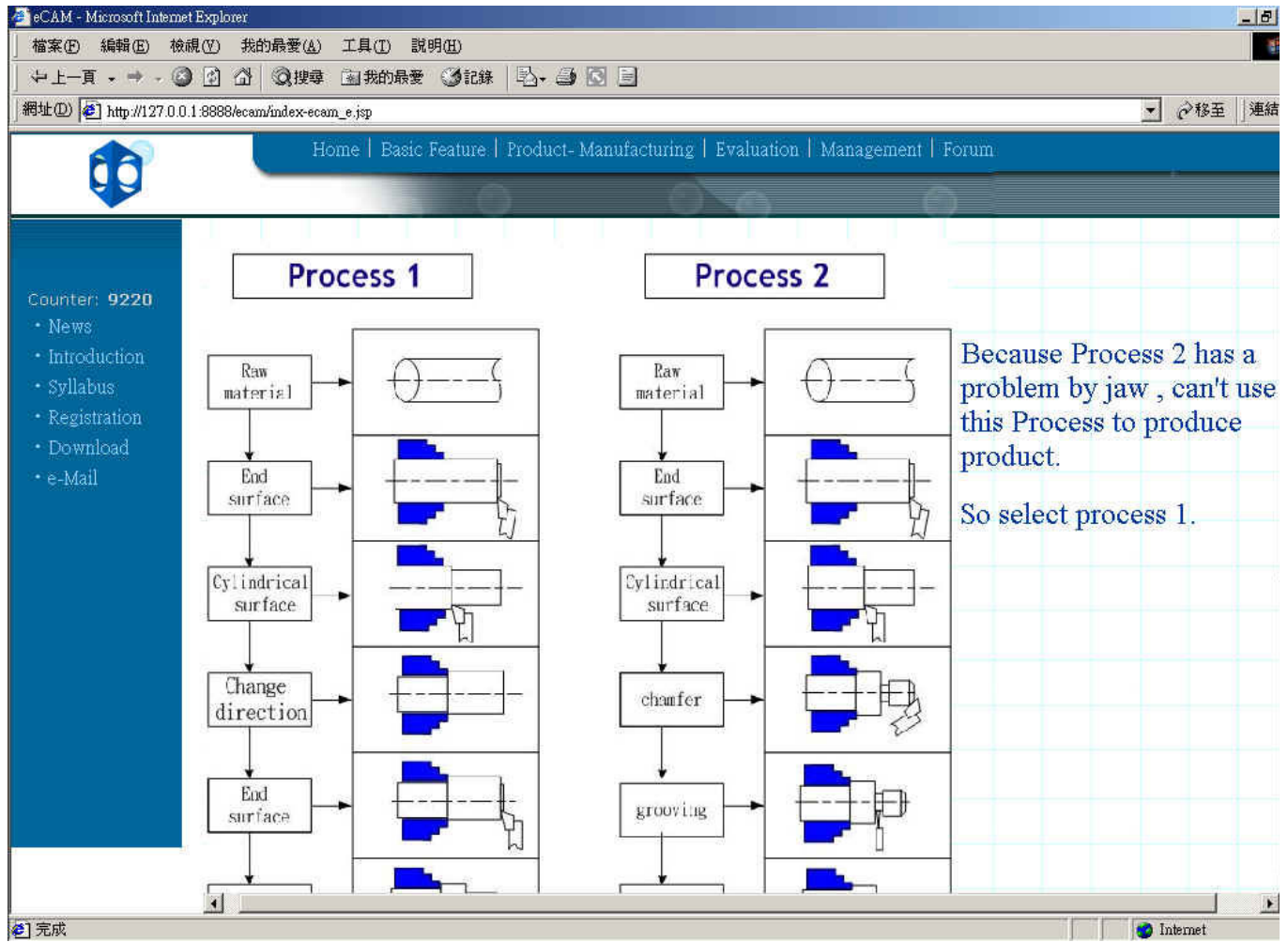

Figure 17 Machining Procedures for a Complex Part 


\subsection{Scenario 4: Learning Agent}

The selection of process parameters, such as cutting tools, cutting speed, feed rate, ...etc., is one of the key issues in machining processes, as shown in Figure 18. Therefore, the mechanism of learning agent is designed in this system, to assist students in learning the process parameters. Once the student inputs incorrect values of process parameters, the learning agent will be triggered automatically, and reference information is given to guide the student to input the correct values (Figure 19).

\subsection{Scenario 5: Virtual Laboratory (VR)}

In order to familiarize students with operation skills before real practice in the laboratory, the virtual laboratory of turning, drilling, and milling is built (Figure 20) to simulate, as real as possible, the functions of machines. Students can operate virtual machines through the interactive control panel, as shown in Figure 21. The VR laboratory, embedded in the learning process, is one of the teaching tools facilitating practice capability.

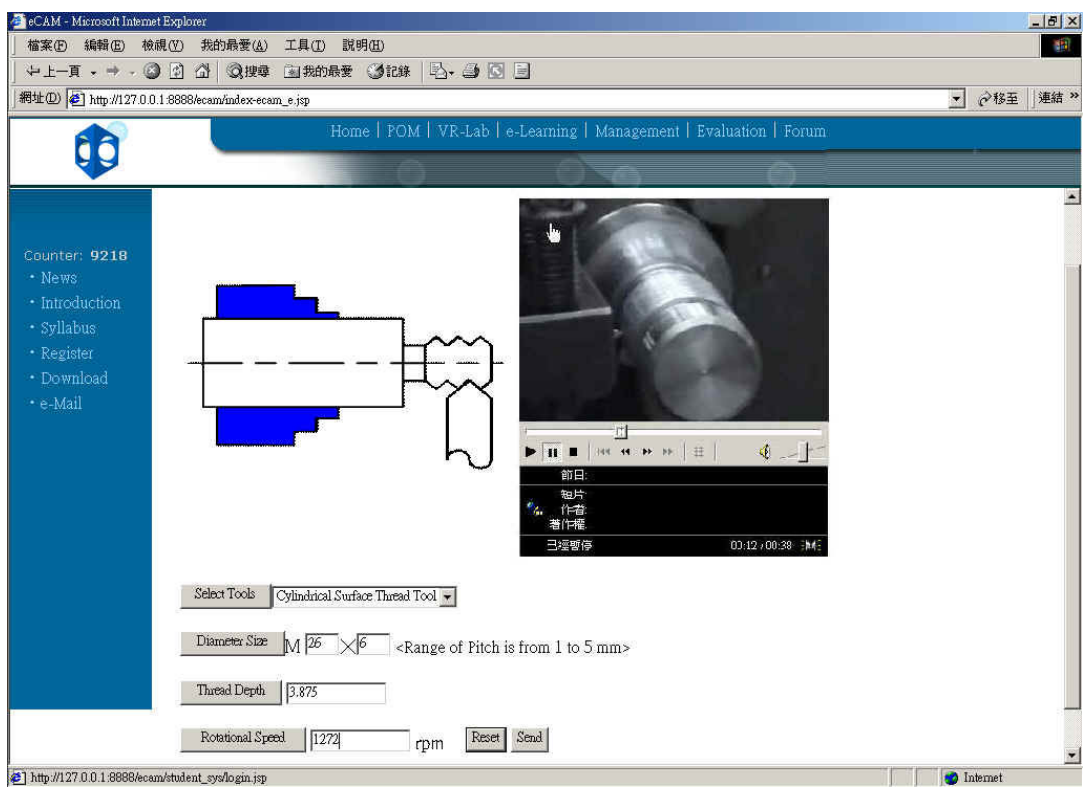

Figure 18 Learning of Process Parameters

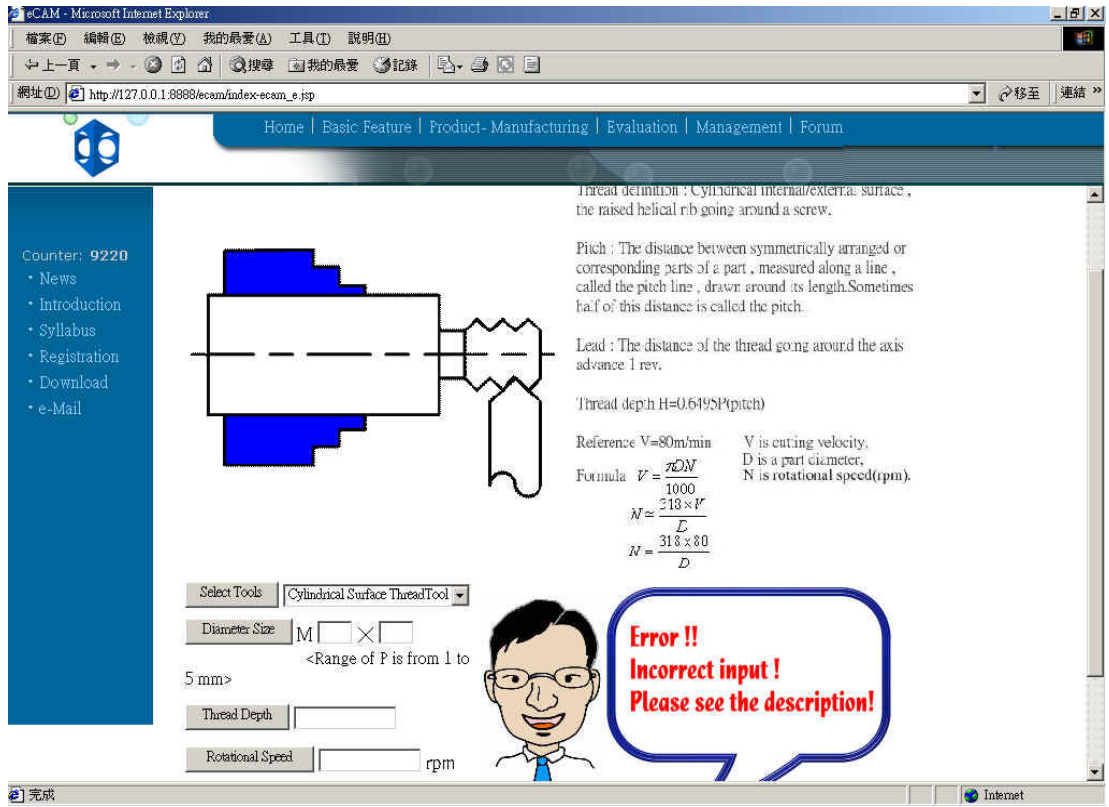

Figure 19 Learning Agent 


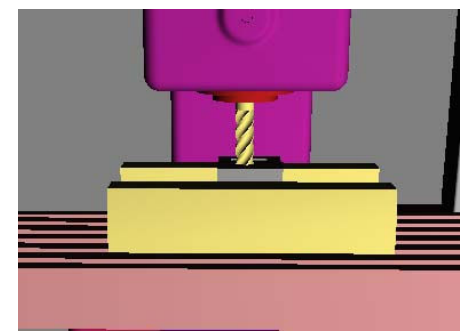

Figure 20 Virtual Laboratory of Machining

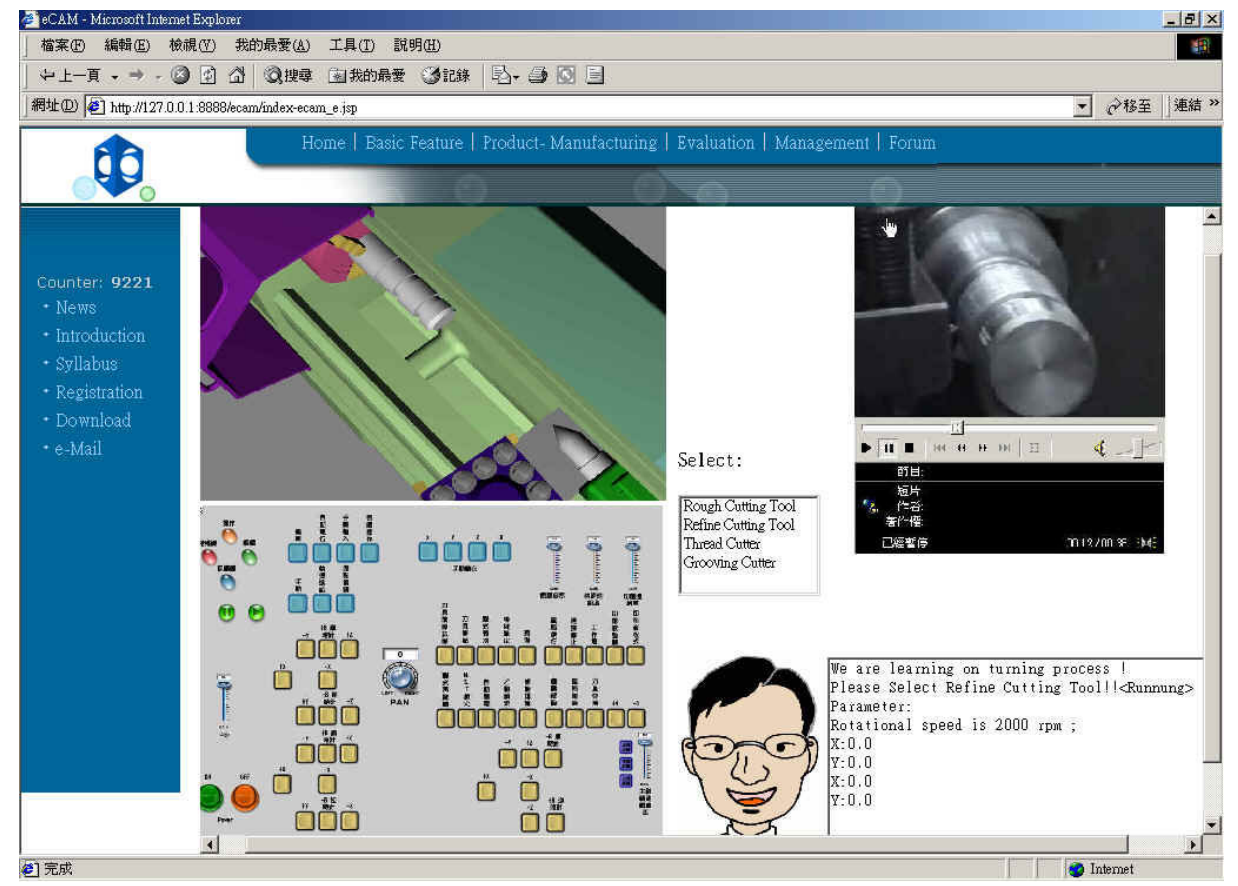

Figure 21 Learning of Turning Process by VR

\subsection{Impact on Manufacturing Education}

The developed Web-based manufacturing education system described here, has been implemented in the undergraduate and vocational high school "machining" course. The impact of the system on manufacturing education is as follows.

(1). The three major parts of manufacturing education include lecture, practice, and evaluation. The instructor needs to teach the lecture course in the classroom, practice in the machining shop, and then evaluate in the traditional method. The developed Web-based manufacturing education system is able to bring the course material to students through the network, as shown in Figure 22. This system can carry out part of the practice through the virtual laboratory. This will advance teaching speed and the quality of practical training in the machining shop. Also, part of the homework assignment and evaluation can be issued and executed through the network.

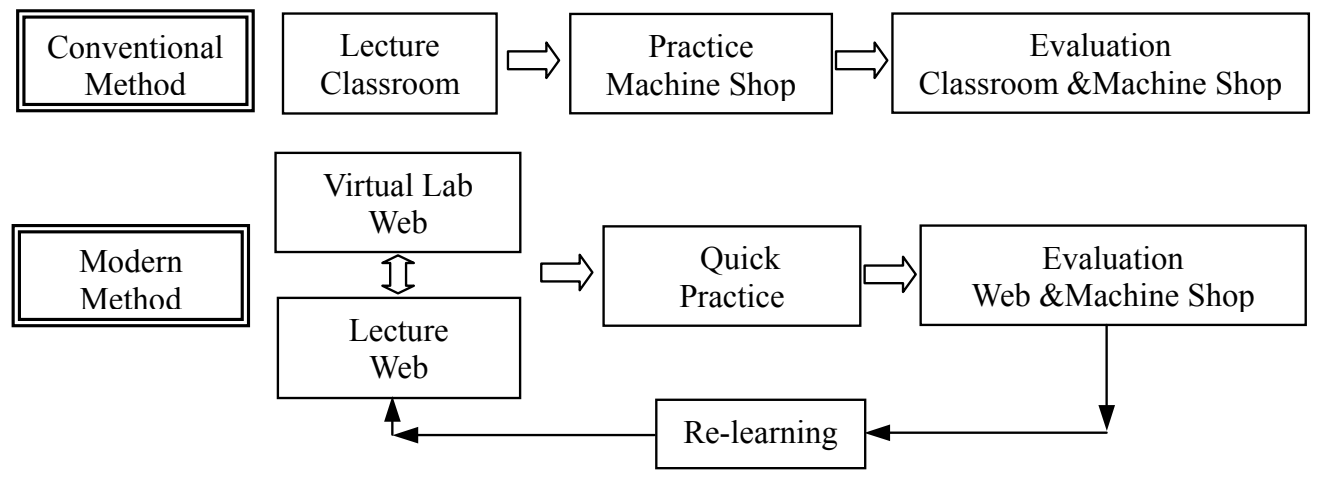

Figure 22 Role of the Developed Web-based Manufacturing Education System 
(2). The developed Web-based learning system improves the safety and efficiency of hands-on machining practice. Students can learn basic machining and experience machining technology through the virtual laboratory before any real practice. In the conventional teaching method, the instructor has to explain all the details of machining operation, including the safety rules. The teaching assistant has to demonstrate the machining operation step by step. The conventional teaching method takes much teaching time. In the modern teaching method, the developed Web-based learning system can allow students to learn the lecture material, and experience the machining operation through the network. This will save the instructor teaching time, and make the teaching of the machining practice go through quicker than ever. Ultimately, the students can have more chance to practice machining.

(3). The developed Web-based learning system allows students to learn and practice the machining techniques repeatedly, and much easier than with conventional teaching ways. In the traditional teaching method, it is difficult to re-practice the machining technology in the machine shop - due to the limitations of machinery and tooling supply, material preparation, practice time schedule .... and so on.

(4). Student feedback indicates the developed Web-based learning system can help reduce their trepidation of the machining operation at an early stage of their hands-on practice.

(5). With the evolution of the Web-based learning system, and when successfully applied to manufacturing education, it becomes possible to divide the total credit hours for a course into lecture, practice, and network teaching hours.

\section{Conclusions}

In this paper, a system of e-learning for manufacturing has been proposed and developed. It demonstrates the methodology of combining XML and Java to implement virtual reality, and Sure Stream media contents. Furthermore, it employs group technology to facilitate effectiveness and standardization of course material, and create sharable course content.

Compared with traditional methods, e-learning of manufacturing has certain advantages. The learning activities are free from time and location. The expensive learning resource of machining techniques can be circulated through the web for the purpose of sharing resources and the diffusion of education. The developed learning method and the virtual laboratory will help the student to improve practice ability.

\section{Acknowledgements}

The author gratefully acknowledges the support of this study by the National Science Council of Taiwan, under the Grant No. NSC91-2516-S-003-002.

\section{References}

(1). EIMaraphy, H.A., "Simulation and Graphical Animation of Advanced Production Systems", Journal of Manufacturing Systems, Volume 1, No.1, 1982, pp.53-63.

(2). Khoshnevis, B., Kiran, A., “A FMS Physical Simulator”, Journal of Manufacturing Systems, Volume 5, No.1, 1986, pp.65-68.

(3). Wald, M.S., "Is a revolution in the classroom coming ?", IJAEE International Journal of Applied Engineering Education, Volume 8, Number 2, 1992, pp.89-91.

(4). Sutherland, R., Facer, K., Furlong, R., Furlong, J., "A New Environment for Education? The Computer in the Home", Computer \& Education, Volume 34, 2000, pp.195-212.

(5). Bengu, G., "Computer-aided Education and Manufacturing Systems with Simulation and Animation Tools", International Journal Engineering Education, Volume 9, Number 6, 1994, pp.484-494.

(6). Bengu, G., "Interactive Multi-media Courseware on Manufacturing Processes and Systems", International Journal Engineering Education, Volume 11, Number 1, 1995, pp.46-57.

(7). Bengu, G. and Swart, W., "A Computer-Aided, Total Quality Approach to Manufacturing Education in Engineering", IEEE Transactions on Education, Volume 39, No.3, August 1996, pp.415-422.

(8). Paquette, G., Ricciardi-Rigault, C., Paquin, C., Liegeois, S., and Bleicher, E., "Developing the Virtual Campus Environment", Proceedings of Ed-Media 96 World Conference on Educational Telecommunication”, Boston, USA, 1996, pp.244-249.

(9). Mikell, P. Groover," Automation, Production Systems, and Computer-Integrated Manufacturing," Second Edition, Prentice Hall, 2001, pp.429.

\section{Biographies}

Min Jou is associate professor in Industrial Education Department at National Taiwan Normal University. He holds an MS degree from University of Missouri - Rolla, and a Ph.D. degree from Rensselaer Polytechnic Institute. His research interests include automation of industrial processes, numerical modeling of manufacturing processes, mechatronics, design and application of electro-optical machines, computer engineering and e-learning education. 